\title{
REDUCTION OF NON-VALUE ADDED ACTIVITIES IN RESTAURANT SERVICES: THE CASE OF BBS-DIZAIN LTD
}

\author{
Inara Jurgena ${ }^{1}$, Dr.oec.; AinaMuska ${ }^{2}$, Dr.oec. and Elina Jurjane ${ }^{3}$, MBA \\ 1,2Latvia University of life Sciences and Technologies, 3 "BBS-Dizain" Ltd
}

\begin{abstract}
In order to ensure the development and competitiveness of an organization, it is essential to continuously enhance processes, particularly those that generate revenue, i.e. business processes, as well as to introduce innovations. One of the business processes at BBS-Dizain Ltd that needs to be enhanced is the catering service. The aim of the research is to examine possibilities for shortening order processing times at BBS-Dizain Ltd. The research concluded that the average rating of order processing time at the restaurant given by the employees of BBS-Dizain Ltd (internal customers) was higher (4 points) than the rating given by visitors (external customers) (3.49 points). A contingency analysis showed that there was no correlation between the ratings given by external and internal customers; therefore, the restaurant's personnel did not critically assess their performance in terms of order processing time. Since changes in the demand for the dishes on the menu of the restaurant exceeded $25 \%$, and none of the dishes on the menu was a leader in terms of revenue generated, there were no dishes, the cooking process of which BBS-Dizain Ltd needed to optimize. The chefs of BBS-Dizain Ltd could enhance their skills in preparing Group AY meals, as the demand for them was relatively steady. Rearranging the workplace of a chef, using the $5 \mathrm{~S}$ methodology, and replacing the worktop for the chef with a freezer allows significantly - two-fold - reducing the number of the steps made during the shift. However, rearranging the restaurant's storeroom, using the 5S methodology, allows saving $95 \%$ time spent on searching for things needed. Therefore, the possibilities to reduce order processing times at the restaurant of BBS-Dizain Ltd involve decreasing unnecessary movements of chefs at their workplaces and reducing the time spent on searching for things in the storeroom.
\end{abstract}

Key words: customer, business process, quality, optimization.

JEL code: M21, L15.

\section{Introduction}

Any entrepreneur or businessperson wants to attract and retain consumers and increase the turnover, market share and profit, while any consumer wants to get the needed goods at the needed place and time and in the needed quantity as well as to get the required quality of service. In order to ensure the development and competitiveness of an organization, including BBS - Dizain Ltd, it is essential to continuously enhance processes, particularly those that generate revenue, i.e. business processes, as well as to introduce innovations.

The following research hypothesis is put forward: an analysis of business processes allows identifying opportunities for enhancement.

One of the business processes at BBS-Dizain Ltd that needs to be enhanced is the catering service.

The aim of the research is to examine possibilities for shortening order processing times at BBS-Dizain Ltd.

Specific research tasks: (1) to justify the need to shorten order processing times at BBS-Dizain Ltd; (2) to test the enhancements identified for the purpose of shortening order processing times; (3) to identify which restaurant cooking process needs to be optimized.

The research employed general scientific research methods, statistical analysis, logical construction, analysis and synthesis as well as experimental methods. The research used unpublished data provided by BBS-Dizain Ltd for the period 01/01/2019-31/12/2019, as well as primary data acquired during the experiments conducted by the authors.

\footnotetext{
${ }^{1}$ Inara Jurgena e-mail:Inara.Jurgena@llu.Iv

2 AinaMuska e-mal: Aina.Muska@llu.Iv

3 Elina Jurjane e-mail:Elina.Jurjane@inbox.Iv
} 


\section{Research results and discussion}

\section{Need for the research}

Upon starting the research on restaurant service enhancement possibilities at BBS-Dizain Ltd, the authors found, based on consumer satisfaction ratings, that the following three components of restaurant performance are the most important for customers: food quality (5 points), waiting time (4.90 points) and personnel attitude (4.89) (Jurgena et al., 2019). After analysing customer satisfaction tree components with regard to quality, the authors concluded that the customers rated table arrangement ( 2.93 points) and waiting time (3.49 points) the lowest. The other components were rated at 4 points and higher. The average rating of the restaurant's service quality was high 4.48 points (Jurgena et al., 2019).

The customer satisfaction index, which was calculated by taking into account the number of respondents who rated the quality of the surveyed parameters at 5 and 4 points, showed that overall the customers of BBS-Dizain Ltd were satisfied with the restaurant's service quality (customer satisfaction index $=88 \%$ ), yet the ratings of waiting time were low: the customer satisfaction index was $42 \%$ out of $100 \%$ or it was more than two-fold lower than the average. Within the research, the restaurant's employees were also surveyed to find out the opinions of the employees or internal customers about the components of the consumer satisfaction tree with regard to quality.

The restaurant's employees rated the importance of waiting time at 4.69 points on a five-point scale (which means the rating was lower than that given by external customers) and waiting time at 4 points (higher than the external customers did). Since the employees themselves did not ensure a high performance of the restaurant, the survey results from both sets of the respondents were compared by doing a contingency analysis to test whether the ratings were dependent on the respondent group. Hypotheses to be tested:

$\mathrm{H}_{0}$ : there is no correlation between the ratings given by customers and the employees;

$\mathrm{H}_{1}$ : there is a correlation between the ratings given by customers and the employees.

Since $\chi^{2}=5.32<\chi_{0.05 ; 3}^{2}=7.81$, the hypothesis $\mathrm{H}_{0}$ may not be rejected; accordingly, there has to be concluded that there is no correlation between the ratings given by customers and the employees.

The maximum probability that the difference in ratings between the two respondent groups could be assumed to be significant is equal to $85 \%$. The authors conclude that the employees were not critical of their performance, and it was also necessary to convince the employees that there was room for enhancement, i.e. shortening waiting times, thereby pointing to a possibility to enhance the order processing process.

\section{Testing the possibility to shorten waiting times}

One way to shorten the waiting time for an order is to reduce the time it takes for a customer's dishes to be ordered.

After analysing the cooking process and its duration, it was concluded that it was possible to reduce the time spent on extra work or unnecessary movements, such as the chef's movements to his/her workplace for the necessary spices, kitchen utensils, inputs etc. In the LEAN system, "movements" are understood as any type of human movement that does not add value but requires both effort and time (Babris et al., 2016). The loss - unnecessary movements - could be minimized or avoided by rearranging the workplace, using the $5 \mathrm{~S}$ methodology. In order to test the suggested enhancement - rearranging the chef's workplace to reduce the unnecessary movements - the authors made a count of the steps made by the same three-chef shift, using bracelets - step 
counters, for 21 days (Chef 1 specialized in soups and main course supplements, Chef 2 - in main courses, Chef 3 - in salads and desserts).

In the first phase of the experiment, the steps made by the chefs before the workplaces had been rearranged were counted during the first seven days (within one chef's working week). At the beginning of the second phase of the experiment, minor changes were made in the workplaces of the chefs - in the arrangement of kitchen equipment and kitchen gadgets -, based on the results of the first phase and the recommendations of the chefs themselves. In addition, at the workplace of Chef 3, a worktop with a shelf system was replaced with a freezer with six drawers, the surface of which began to function as a worktop as well. The worktop was replaced only for Chef 3 , as the experimenters had only one freezer at their disposal. After consulting the chefs, the decision was made to change the worktop for Chef 3, as the chef specialized in making salads, which were traditionally ordered as a first course meal at a restaurant, and this time should be shortened. In the second phase of the experiment, for 14 days (two weeks) in a row (days 8 to 21), the steps of the chefs were counted again. The results of the experiment are shown in Table 1.

\section{Number of steps made by the chefs before and after the rearrangement of} their workplaces at BBS-Dizain Ltd

\begin{tabular}{|c|c|c|c|c|c|}
\hline \multirow{3}{*}{ Indicator } & \multicolumn{4}{|c|}{ Experiment } & \multirow{3}{*}{$\begin{array}{c}\text { Difference } \\
\text { between } \\
\text { Phase I and } \\
\text { Phase II } \\
\text { average }\end{array}$} \\
\hline & \multirow{2}{*}{$\begin{array}{l}\text { Phase I } \\
\text { Days 1-7 }\end{array}$} & \multicolumn{3}{|c|}{ Phase II } & \\
\hline & & Days 8-14 & Days 15-21 & $\begin{array}{l}\text { Phase II } \\
\text { average }\end{array}$ & \\
\hline \multicolumn{6}{|c|}{ Chef 1: soup and main course supplements } \\
\hline Number of orders & 631 & 549 & 480 & 515 & -116 \\
\hline Steps made, thou. & 108.9 & 100.5 & 102.82 & 101.7 & -7.2 \\
\hline Average number of steps made a day & 15557 & 14357 & 14689 & 14523 & -1034 \\
\hline \multicolumn{6}{|c|}{ Chef 2: main courses } \\
\hline Number of orders & 631 & 549 & 480 & 515 & -116 \\
\hline Steps made, thou. & 100.7 & 97.8 & 93.2 & 95.5 & -5.2 \\
\hline Average number of steps made a day & 14386 & 13971 & 13314 & 13643 & -743 \\
\hline \multicolumn{6}{|c|}{ Chef 3: salads and desserts } \\
\hline Number of orders & 471 & 384 & 322 & 353 & -118 \\
\hline Steps made, thou. & 87.2 & 41.2 & 38.0 & 39.6 & -47.6 \\
\hline Average number of steps made a day & 12457 & 5886 & 5429 & 5657 & -6800 \\
\hline
\end{tabular}

Source: experimental results

The experimental data show that more activity in terms of number of steps made by all the three chefs was observed on Fridays (experimental days 4,11,18), as preparatory work was done in preparation for the weekend, Saturday and Sunday, when more orders were taken, and on Mondays (experimental days 7, 14, 21), when preparations were made for the change of a shift (room cleaning etc.).

As shown in Table 1, after the workplace was rearranged, the number of steps made by Chef 3 decreased by 6.8 thou. per day, or $55 \%$, which was significant progress. Chef 3 positively viewed the results and wanted to keep the workplace arrangement created for the experiment.

No significant positive effect was found for Chefs 2 and 3: the number of steps made by Chef 1 decreased by 1034 or $7 \%$, while for Chef 2 the decrease was 743 steps or $5 \%$. An analysis of the cooking process allows assuming that a significant decrease in the number of steps made by Chefs 1 
and 2 could be observed if replacing a worktop with a shelf system with a freezer with six drawers at their workplaces.

In view of the fact that during order processing, including during the experiment, it was necessary for the chefs to find and bring various things from the kitchen's storeroom to their workplaces, it was assumed that the order processing time (cooking time) could also be reduced by reducing the time spent on searching for things in the storeroom. The authors conducted a second experiment - the time spent on finding necessary things was recorded by means of a stopwatch both before and after the rearrangement of the storeroom. The results of the experiment are shown in Table 2.

Average time spent by the chefs of BBS-Dizain Ltd on searching for things in the storeroom before and after the rearrangement of the storeroom

\begin{tabular}{|c|c|c|c|c|}
\hline \multirow{2}{*}{ Things needed } & \multicolumn{2}{|c|}{ Time spent on finding things, seconds } & \multicolumn{2}{|c|}{ Time savings, } \\
\hline & $\begin{array}{l}\text { before } \\
\text { rearrangement }\end{array}$ & after rearrangement & seconds & $\%$ \\
\hline Receipt tape for kitchen printers & 227 & 3 & 224 & 99 \\
\hline Heat-retaining platform & 141 & 5 & 136 & 96 \\
\hline Serving bowl & 182 & 5 & 177 & 97 \\
\hline
\end{tabular}

Source: experimental results

In the result of the experiment, it was found that the main problems regarding finding things in the storeroom for the chefs were because of:

- absence of signs on boxes and shelves in the storeroom;

- difficulty in finding things;

- presence of defective containers in the storeroom.

During the experiment, the storeroom was rearranged, using the $5 S$ methodology, i.e. all the things in the storeroom were sorted, disposing of unnecessary things; the necessary things were arranged in a clear way, using visual guidance (boxes were labelled with the names and pictures of the things they contained; signs were placed on shelves, showing the things being placed on them). Before the storeroom was rearranged, the authors performed an analysis of the intensity of use of things to identify the most appropriate place for each thing: the things used less frequently were placed at farther corners, while the things needed more frequently were placed closer to the front door, and heavier items were placed on lower shelves. In the result of rearranging the storeroom, some space was freed up, which, upon the recommendation of the employees, was used for the storage of disposable containers formerly placed in the root vegetable storeroom, which was far away from the chefs' workplaces. Consequently, not only did it reduce the time it took to find more than $95 \%$ of the things, but it also reduced the number of steps to be made to bring disposable packaging and reduced the risk for the employees to get injured when carrying heavy things from the top shelves.

\section{Analysis of the menu of the restaurant}

An ABC - XYZ analysis of the dishes offered by the restaurant was performed, thereby identifying which product categories (dishes) were in demand and the changes in order to find out which food preparation processes the chefs could optimize in order to shorten the cooking times (Table 3). 
ABC - XYZ combined analysis of BBS-Dizain Ltd products

\begin{tabular}{|c|c|c|c|c|}
\hline \multirow{2}{*}{\multicolumn{2}{|c|}{ Indicator }} & \multicolumn{3}{|c|}{ Value Share } \\
\hline & & A (high) & B (moderate) & $C($ low $)$ \\
\hline \multirow{3}{*}{ 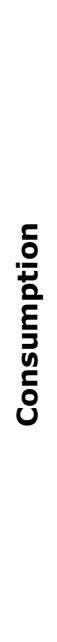 } & $\begin{array}{c}\mathrm{X} \\
\text { (constant) }\end{array}$ & $\begin{array}{l}\text { High value percentage } \\
\text { Continuous demand } \\
\text { High predictive value }\end{array}$ & $\begin{array}{l}\text { Average value percentage } \\
\text { Continuous demand } \\
\text { High predictive value }\end{array}$ & $\begin{array}{l}\text { Low value percentage } \\
\text { Continuous demand } \\
\text { High predictive value }\end{array}$ \\
\hline & $\begin{array}{c}\mathrm{Y} \\
\text { (unsteady) }\end{array}$ & $\begin{array}{l}\text { High value percentage } \\
\text { Fluctuating demand } \\
\text { Average predictive value } \\
\text { 7; 28; 23; 37; 13; 9; 4; } \\
\mathbf{2 1 ; ~ 5 1 ~}\end{array}$ & $\begin{array}{l}\text { Average value percentage } \\
\text { Fluctuating demand } \\
\text { Average predictive value } \\
\mathbf{4 4}\end{array}$ & $\begin{array}{l}\text { Low value percentage } \\
\text { Fluctuating demand } \\
\text { Average predictive } \\
\text { value }\end{array}$ \\
\hline & $\begin{array}{c}Z \\
\text { (sporadic) }\end{array}$ & 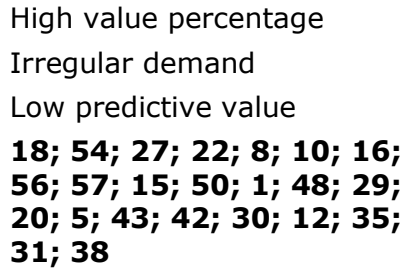 & $\begin{array}{l}\text { Average value percentage } \\
\text { Irregular demand } \\
\text { Low predictive value } \\
\text { 40; 47; 25; 53; 58; 52; } \\
\mathbf{4 9 ;} \mathbf{3 4 ; ~ 2 ; ~ 1 4 ; ~ 1 1 ; ~ 3 9 ; ~ 3 2 ; ~} \\
\mathbf{5 5}\end{array}$ & $\begin{array}{l}\text { Low value percentage } \\
\text { Irregular demand } \\
\text { Low predictive value } \\
\text { 33; 6; 45; 26; 19; 24; } \\
\text { 36; 3; 41 }\end{array}$ \\
\hline
\end{tabular}

An analysis of the data revealed that changes in the demand for most of the dishes were significant, i.e. more than $25 \%$ (Group Z). There was no constant demand for any dish on the menu (Group X; changes in demand reached $10 \%$ ). Changes in the demand for nine dishes (Group AY) (i.e. Baked Salmon in Cream (7), Salmon Tartare (28), Lamb Soup with Vegetables (23), Bread with Herb Butter (37), Toasted Bread with Cheese Sauce (13), Creme Brulee (9), Cottage Cheese Dessert with Cranberry Sauce (4), Grilled Chicken Skewer (21), Strudel (51)) were medium, and the dishes belonged to a product group (Group A) that generated $80 \%$ of the restaurant's total revenue.

The proportion of revenue generated by each individual dish served by the restaurant in the total revenue was low, ranging from 4.5\% (Grilled Pork Ribs (18)) to $0.1 \%$ (Pasta without Sauce (41)), which means that none of the dishes offered by the restaurant was a leader in terms of revenue generated.

The authors might recommend the chefs to pay special attention to the nine dishes in Group AY, trying to optimize the cooking process and applying more skills in preparing the dishes, as the dishes generated the basic revenue for the restaurant and ensured a relatively steady demand.

\section{Conclusions and recommendations}

1) The average rating of order processing time at the restaurant given by the employees of BBSDizain Ltd (internal customers) was higher (4 points) than the rating given by visitors (external customers) (3.49 points). A contingency analysis showed that there was no correlation between the ratings given by external and internal customers; therefore, the restaurant's personnel did not critically assess their performance in terms of order processing time.

2) Since changes in the demand for the dishes on the menu of the restaurant exceeded $25 \%$, and none of the dishes on the menu was a leader in terms of revenue generated, there were no dishes, the cooking process of which BBS-Dizain Ltd needed to optimize. The chefs of BBS-Dizain Ltd could enhance their skills in preparing Group AY meals, as the demand for them was relatively steady. 
3) Rearranging the workplace of a chef, using the $5 S$ methodology, and replacing the worktop for the chef with a freezer allows significantly - two-fold - reducing the number of the steps made during the shift. However, rearranging the restaurant's storeroom, using the $5 \mathrm{~S}$ methodology, allows saving $95 \%$ time spent on searching for things needed. Therefore, the possibilities to reduce order processing times at the restaurant of BBS-Dizain Ltd involve decreasing unnecessary movements of chefs at their workplaces and reducing the time spent on searching for things in the storeroom.

\section{Bibliography}

1. Babris S., Kalkis H., Murnieks J., Piekuss U. (2016) LEAN risinajumi efektivakam biznesam. Monografija (LEAN Solutions for Effective Business. Monograph). Riga, 187 p.

2. BBS-Dizain Ltd. (2019). Internal data.

3. Gurel, D. A. (2013). A Conceptual Evaluation of 5S Model in Hotels. African Journal of Business Management, $7(30), 3035$.

4. Jurgena, I., Muska, A., Jurjane, E. (2019). Ratings of Consumer Satisfaction: the Case of BBS-Dizain Ltd. Proceedings of the international scientific conference Economic Science for Rural Development, No. 50, pp. 78-83, Retrieved: http://www.esaf.Ilu.Iv/sites/esaf/files/files/lapas/Latvia_ESRD_50_2019.pdf. ISBN 9789984483207. ISSN 2255-9930. Access: 15.01.2020.

5. Pandya, B., \& Thakkar, H. (2016). A Review on Inventory Management Control Techniques: $A B C-X Y Z$ analysis. REST Journal on Emerging trends in Modelling and Manufacturing, 2, 15. Retrieved: http://restpublisher.com/wp-content/uploads/2016/09/A-Review-on-Inventory-Management-ControlTechniques-ABC-XYZ-Analysis.pdf. Access: 15.01.2020. 